\title{
Lymphocytic duodenitis or microscopic enteritis and gluten-related conditions: what needs to be explored?
}

\author{
Enzo lerardia , Giuseppe Losurdo a , Andrea lannone a, Domenico Piscitellib, Annacinzia Amoruso ${ }^{a}$, \\ Michele Barone ${ }^{a}$, Mariabeatrice Principi ${ }^{a}$, Antonio Pisania ${ }^{a}$ Alfredo Di Leo ${ }^{a}$
}

AOU Policlinico, Piazza Giulio Cesare, Bari, University of Bari, Italy

\section{Abstract}

aSection of Gastroenterology (Enzo Ierardi, Giuseppe Losurdo, Andrea Iannone, Annacinzia Amoruso, Michele Barone, Mariabeatrice Principi, Antonio Pisani, Alfredo Di Leo); 'Section of Pathology (Domenico Piscitelli), Department of Emergency and Organ Transplantation, AOU Policlinico, Piazza Giulio Cesare, Bari, University of Bari, Italy

Conflict of Interest: None

Correspondence to: Prof. Enzo Ierardi, Section of Gastroenterology, Department of Emergency and Organ Transplantation, AOU Policlinico, Piazza Giulio Cesare, Bari, University of Bari, Italy, Tel.: +39080 5594033, Fax: +39080 5593088, e-mail: ierardi.enzo@gmail.com

Enzo Ierardi and Giuseppe Losurdo are co-first authors

Received 12 April 2017; accepted 10 May 2017; published online 31 May 2017

DOI: https://doi.org/10.20524/aog.2017.0165

\section{Introduction: Definition of microscopic enteritis (ME)} and epidemiology

An abnormal infiltration of intraepithelial lymphocytes (IELs) in the gastrointestinal mucosa is a common feature of several diseases, both gluten-mediated and non-glutenrelated [1]. It has been regarded as duodenal lymphocytosis or lymphocytic duodenitis in the past, but the recent Bucharest Consensus has proposed the new entity of ME as an umbrella term to describe this condition $[2,3]$.

IELs are a usual element among the cells harvesting intestinal mucosa, and a number of 11-25 IELs per 100 enterocytes is considered normal [4-6]. However, a number exceeding 25 per 100 enterocytes (the so-called Marsh I stage) is regarded as a pathologic feature [7]. Nevertheless, this should not be considered as a strict cutoff value, since the distribution and the density of IEL infiltrate balance along the alimentary 
tract is irregular. For this reason, the diagnosis of ME is often difficult and relies on the expertise of the pathologist.

As already stated, several diseases may imply ME. For this reason, it is viewed as a quite common condition with an increasing trend over time. Galli et al [8] found the prevalence of $\mathrm{ME}$ to be $6.2 \%$ in a retrospective database of 7000 duodenal biopsy samples and, interestingly, reported a fivefold increase from 2010 to 2013, especially for non-gluten related disorders. Another two studies reported a prevalence of ME of $1.3 \%$ and $2.2 \%$, respectively $[9,10]$. Shmidt et al [11] described a prevalence of $4.3 \%$ in a pediatric population and, in another study, showed an increase from $3 \%$ to $10.9 \%$ over a 10 -year period [12]. All these studies agree that the increasing prevalence of ME may be due mainly to conditions other than celiac disease and that females are more frequently affected than males.

Based on these reports, ME represents a novel entity that is attracting increasing interest. However, ME is a complex condition; therefore, the knowledge of the importance and the role that IELs play in mucosal immunity is fundamental before we analyze the individual conditions that may lead to ME.

\section{The role of IELs in immune homeostasis}

The intestinal mucosa is a pivotal contact barrier between the body and the environment. For this reason, it has continuous direct interaction with external antigens. As a consequence, the intestinal mucosa contains a huge population of immunity cells that regulate the interface between the human organism and germs and non-self antigens. In this context, IELs play a relevant role.

IELs are T-lymphocytes whose main function is to maintain immune surveillance. They are powerfully stimulated by several intraluminal factors, such as ingested antigens and gut microorganisms; therefore, their phenotype and function may

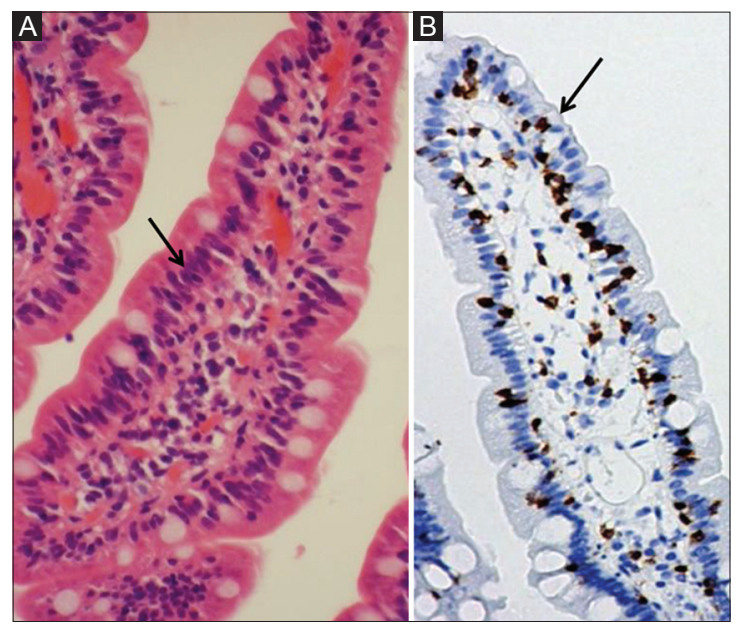

Figure 1 Histopathologic picture of microscopic enteritis. On the left, (A) a hematoxylin-eosin staining of a duodenal villus. Intraepithelial lymphocytes (IELs) are indicated by the arrow. On the right, (B) IELs are identified by immunohistochemistry for $\mathrm{CD} 3$ (brown staining) vary along the intestinal tract [13]. Immunohistochemistry for CD3 is the most useful tool for detecting them in biopsy samples (Fig. 1). However, IELs often have a complex phenotype. Indeed, many subclasses have been described, according to clusters of differentiation and related T-cell receptor subtypes and specific functions [14]:

1. IELs CD $4 \alpha \beta$ are specifically expressed in the colon and produce interleukin (IL)-10, with anti-inflammatory properties

2. IELs CD8 $\alpha \beta$ CD94+ are able to cooperate with natural killer cells, activating them when IELs interact with some antigens

3. IELs CD8 $\alpha \beta$ CD94- are the main interferon- $\gamma$ producers; therefore, they are able to mount an inflammatory response directly

4. IELs $\gamma \delta$ represent a small percentage of IELs, but they play an important role in cell-mediated immunity.

The interaction between $\alpha \beta$ and $\gamma \delta$ IELs is essential to balance the immune tolerance and the response to antigens. When inflammatory stimuli occur, the $\alpha \beta$ IELs upregulate the natural killer receptors, promote the production of proinflammatory cytokines, such as tumor necrosis factor- $\alpha$ and interferon- $\gamma$, and induce the lysis of infected enterocytes by releasing both perforin and granzyme B $[15,16]$.

Therefore, IELs act as modulating cells in the process of antigen presentation. It is known that, in celiac disease, antigen-presenting cells pass gluten immunogenic peptides to T-lymphocytes in the lamina propria [17]. Following gluten stimulation, a marked proliferation of T-helper lymphocytes and an increased production of inflammatory cytokines, mainly interferon- $\gamma$, characterize the celiac intestinal mucosa. Remarkably, gluten-specific CD4+ T-cells can be isolated from the small intestinal biopsy samples of celiac disease patients and not from non-celiac controls, thus underlining their pathogenic relevance [18]. Despite the pivotal role played by CD4+ T-lymphocytes in the pathogenesis of celiac disease, recent evidence suggests that CD8+ T-cells are also involved in the inflammatory cascade elicited by the gluten. Therefore, IELs are both regulatory cells and main actors in the pathogenesis of celiac disease. Nevertheless, IELs are also agents of innate immunity; therefore, they are self-activated even if stimulated by antigens other than gliadin, such as bacteria, drugs and foods [19]. For this reason, they are involved in the development of all types of ME.

\section{Origin of ME}

\section{Celiac disease}

Celiac disease is the most common autoimmune enteropathy, triggered by the ingestion of protein molecules (gliadin, secalin, hordein) contained in wheat and associated species of barley, rye and oats [20]. A genetic predisposition is frequent, with most subjects being carriers of human leukocyte antigen (HLA) DQ2 or DQ8. The mucosal damage is mediated by either innate or adaptive immunity. In this regard, Fig. 2 summarizes the pathogenesis of the different forms of ME. 


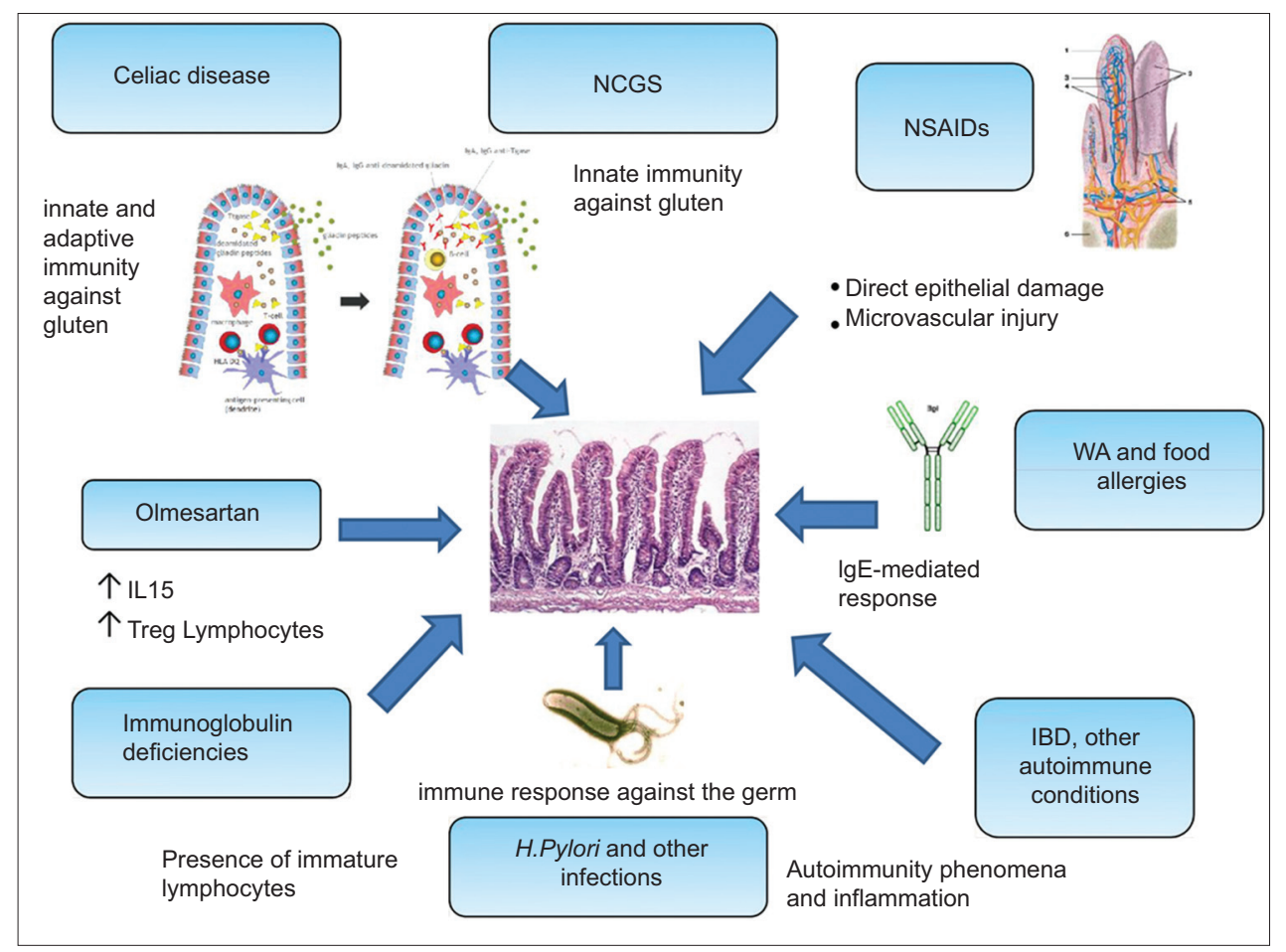

Figure 2 Different pathogenic mechanisms of microscopic enteritis.

NCGS, non-celiac gluten sensitivity; NSAIDs, non-steroidal anti-inflammatory drugs; IL, interleukin; WA, wheat allergy; IBD, inflammatory bowel disease

The degree of mucosal damage in celiac disease has been classified according to the Marsh staging. In this classification, a picture of duodenal lymphocytosis may be given a grade of 1, characterized by an infiltrate of more than 25 IELs/100 enterocytes. Although these subjects do not display a villous atrophy, they often show signs of malabsorption, such as anemia and osteopenia [21]. In contrast to non-gluten related causes of ME, they may reveal a clinical picture characterized by extraintestinal manifestations of celiac disease [22].

Notably, it has been reported that celiac patients with minimal mucosal alterations are less frequently positive for anti-transglutaminase and anti-endomysium antibodies than those with villous atrophy [23]. The condition marked by mild enteropathy, celiac disease and negative serology has been described as seronegative celiac disease [24,25]. A conflicting debate has arisen in this context, since some researchers do not acknowledge the need for a gluten-free diet and suggest a watch-and-see strategy until serology becomes positive [26]. Others recommend a gluten-free diet, since simultaneous mucosal inflammation and extraintestinal manifestations have been described in this condition $[27,28]$.

\section{Non-celiac gluten sensitivity}

Non-celiac gluten sensitivity is a novel nosological entity in the panorama of gluten-related disorders. It is characterized by both gastrointestinal symptoms (abdominal pain, diarrhea, bloating) and extra-digestive manifestations, such as weakness, headache, joint pain or sometimes depression [29]. This cohort of symptoms is linked to gluten ingestion, and it has been demonstrated that their onset shortly follows gluten exposure, in contrast to celiac disease, where a latency time of several weeks is usual [30]. Several experimental studies have shown a selective involvement of innate immunity in nonceliac gluten sensitivity, suggested by the elevation of Toll-like receptor expression (Fig. 2) [31,32]. This immune mechanism seems to be unbound from possible genetic susceptibility, since positivity of DQ2/8 haplotypes has been described in only $50 \%$ of cases. Auto-antibodies typical of celiac disease are usually absent, and only anti-native gliadin antibodies tested positive in half of populations with non-celiac gluten sensitivity [33]: this finding adds further support to the hypothesis of an exclusive involvement of innate immunity in non-celiac gluten sensitivity. Recently, some studies have suggested that the triggering factor might not be gliadin, but other components of wheat, such as amylase-trypsin inhibitors or fermentable oligosaccharides, disaccharides, and polyols [34,35]; for this reason, the alternative nomenclature of non-celiac wheat sensitivity has been proposed [36].

Given the absence of a specific marker or a characteristic clinical picture, the diagnosis of non-celiac gluten sensitivity is based solely on the exclusion of other possible diseases and the gluten-free diet represents the only effective treatment. Indeed, non-celiac gluten sensitivity is an emerging disease. While early studies identified a prevalence of up to 6\% [37], nowadays the possibility of the nocebo effect biasing glutenrelated symptoms has led to the emergence of rigorous criteria (Salerno consensus) to diagnose non-celiac gluten sensitivity. This consensus advised a double-blind crossover gluten 
challenge [38]. The application of these criteria has proven that true non-celiac gluten sensitivity has been overestimated in the past years. Indeed, a recent study that started with a sample size of 140 patients with clinical suspicion of this condition reported that only $14 \%$ were recognized as true non-celiac gluten sensitivity after this diagnostic workup [39].

Non-celiac gluten sensitivity is commonly associated with ME. The histological analysis of duodenal biopsy samples usually finds a Marsh 0 or I grade enteropathy. Increased IEL infiltration is observed in up to $25 \%$ of patients [40,41]. The presence of a linear T-lymphocyte infiltration in the lamina propria, occurring in about $78.5 \%$ of patients, has been proposed as a distinct feature in a single-center experience, but at the moment there is only the single report [42]. Finally, an increase in eosinophils has also been described [43]. However, such histological pictures represent only case series reports, and the specific microscopic characteristics of non-celiac gluten sensitivity have not been yet established.

\section{Wheat allergy}

Wheat allergy is an allergic condition triggered by grain protein ingestion. The mechanism may be mediated by specific IgE or cellular immunoreaction (Fig. 2) [44]. It is often associated with other allergic manifestations, such as asthma (48-67\%) or allergic rhinitis (34-62\%) [45]. Symptoms occur from a few min to $2 \mathrm{~h}$ following wheat consumption. In young children, gastroenterological manifestations, such as vomiting, diarrhea or abdominal pain, are more common [46]. Cutaneous signs (urticaria, erythema, angioedema, itching) are observed in about $40 \%$. In adults, wheat allergy is associated with respiratory disorders (wheeze, stridor, persistent cough, hoarse voice, respiratory distress, nasal congestion) and, in the most severe cases, anaphylaxis [47]. Wheat-dependent exercise-induced anaphylaxis is a rare form of IgE-mediated anaphylactic reaction occurring 10-60 min after physical exercise within $10 \mathrm{~min}$ to $4 \mathrm{~h}$ following wheat ingestion [48].

Wheat allergy diagnosis relies on allergy tests. First-line examinations are skin tests for wheat flour, such as skin prick tests, which investigate cellular-mediated reactions. A further step consists in the evaluation of serum concentrations of allergen-specific IgE to whole wheat extract. Finally, glutenspecific IgE can also be assessed [44].

ME may occur in the context of wheat allergy, but other microscopic characteristics are an increase in mucosal basophil and eosinophil granulocytes [49]. Unfortunately, studies investigating the duodenal histology of wheat allergy are rare; it is therefore impossible to establish a clear association between $\mathrm{ME}$ and wheat allergy.

\section{Dermatitis herpetiformis}

Dermatitis herpetiformis may be a skin manifestation of celiac disease, presenting with blistering rash and typical cutaneous IgA deposits [50]. In dermatitis herpetiformis, IgA are present in the skin, and inflammatory cells and cytokines are found in the lesions. Furthermore, antiendomysium and anti-transglutaminase antibodies occur in the serum, and the rash is gluten-sensitive. Small erythematous macules are initially observed and rapidly develop into urticarial papules and small vesicles, which may split, dry, and form scabs. Predominant symptoms are itching and burning. The rash has a characteristic symmetrical distribution. Elbows and upper forearms are involved in more than $90 \%$. Other common sites are buttocks, knees, shoulders, sacrum, face, scalp, neck and trunk. This characteristic rash undergoes a rapid improvement after a gluten-free diet. Moreover, antibodies to both tissue and epidermal transglutaminase are usually found in the serum of patients with dermatitis herpetiformis [51]. Only a minority of patients, about $10 \%$, have mild gastrointestinal symptoms. Villous atrophy in the upper small intestinal mucosa is found in $65-75 \%$ of patients with dermatitis herpetiformis. Even in patients with apparently normal biopsies, subtle changes in the mucosa, such as an increased number of IELs, may suggest a gluten sensitization [52,53]. Reunala et al [54] reported a condition of ME in $61 \%$ of patients with dermatitis herpetiformis, irrespectively of the presence of gastrointestinal symptoms.

\section{Allergy to alimentary proteins}

Allergy to cows' milk, soy products, fish, rice, and chicken has been associated with ME. Variable degrees of villous alteration with crypt hyperplasia may be seen [55]. A patchy enteropathy was found in $60 \%$ of patients with cows' milk allergy, in all cases characterized by duodenal lymphocytosis [56]. A striking increase in $\gamma / \delta$-positive T-cells has been reported in such patients $[57,58]$. Further diagnostic clues are increased eosinophils and the association with clinical manifestations of an allergic phenotype.

\section{Autoimmune enteropathy}

Autoimmune enteropathy is rare condition characterized by severe and prolonged diarrhea and malabsorption with weight loss. It is due to autoimmune phenomena targeting intestinal mucosa [59]. The production of autoantibodies against enterocytes or goblet cells is the main pathogenetic mechanism. Therefore, the detection of such autoantibodies in the serum is the main diagnostic tool. Autoimmune enteropathy usually develops in infants and young children, although some cases have been recorded in adults [60]. Small intestinal histopathology usually includes various degrees of villous atrophy, IEL infiltration in the enterocyte layer and lamina propria, apoptotic bodies and crypt hyperplasia. IELs are more plentiful in the crypts than in the surface and villous tips [61]. 


\section{Inflammatory bowel disease and other autoimmune conditions}

Inflammatory bowel diseases are chronic autoimmune disorders of the alimentary tract. They show a complex pathogenesis, which has not been completely elucidated so far. Ulcerative colitis and Crohn's disease are the two most common phenotypic manifestations of inflammatory bowel disease. In particular, Crohn's disease may involve the entire gastrointestinal system, and a duodenal localization has been reported in $28.2 \%$ of patients [62]. In this subset of patients, the macroscopic appearance of the mucosa shows ulcers or erythema. Microscopic examination of the duodenum usually reveals a picture mimicking celiac disease. For this reason, ME in Crohn's disease should prompt a differential diagnosis between concomitant celiac disease and a duodenal localization [63]. Although a transmural inflammation and granulomas are a rare finding in endoscopic biopsy samples, they could help in the differential diagnosis, being a particular feature of Crohn's disease. ME has been reported even in ulcerative colitis: Vidali et al [64] identified an abnormal IEL infiltrate in $26.6 \%$ of patients, with a significant increase in CD3- and CD8-positive cells.

Other autoimmune disorders associated with non-specific ME are rheumatoid arthritis, vasculitides, connective tissue disorders, autoimmune thyroiditis, psoriasis and multiple sclerosis [65-70].

\section{Helicobacter pylori (H. pylori) and other infections}

H. pylori is the major cause of chronic gastritis. However, it has been demonstrated that it is one of the most common causes of ME. In a group of patients with functional dyspepsia, a direct relationship was demonstrated between the presence of H. pylori and ME [71]. Furthermore, in a Spanish prospective study, $H$. pylori was considered as the starting point for $24.4 \%$ of ME cases [72], while $19 \%$ of subjects with ME had positivity for H. pylori in an Italian series [73]. Additionally, Memeo et al showed that duodenal IELs from patients with $H$. pylori gastritis ranged from 3-42 lymphocytes per 100 enterocytes (mean 18.5) compared to 3-18 lymphocytes/100 epithelial cells (mean 6.6) in the control group [74]. IEL elevation was seen in $44 \%$ of duodenal biopsies from patients with $H$. pylori gastritis, a significantly higher percentage than in the control group. Finally, a significant reduction in IELs was reported after successful eradication [75]. Conversely, one single study found no correlation between the density of IELs and concomitant $H$. pylori infection [75].

Since $H$. pylori selectively colonizes the gastric mucosa, possible mechanisms for ME occurrence have been hypothesized: i) ME could be a simple epiphenomenon of the infection; ii) a passive, perhaps transendothelial, migration and accumulation of IELs could occur; and iii) acid-induced injury may be a possible stimulation for intraepithelial lymphocytosis [77-79].

Among parasitic infections, Giardia duodenalis and Criptosporidium may cause both intraepithelial lymphocytosis and villous atrophy. The clinical manifestations (abdominal pain and watery diarrhea), along with the histological picture, often resemble celiac disease. In these cases eosinophilia may occur and a careful examination may identify the parasite in biopsy and fecal samples [80-82]. Elevated IELs count are also found in viral enteritis [83].

Tropical sprue [84] is a diarrheic disease that is common in patients living in tropical regions. It is believed to be caused by infective agents, but a single species has not yet been recognized: indeed, it has been hypothesized that enteric coliform organisms could underlie this disease. The histological picture is very similar to celiac disease, but concomitant eosinophilia is frequent and inflammatory changes are often seen along the whole small bowel [84].

Small intestinal bacterial overgrowth (SIBO), when related to gastric hypochlorhydria or intestinal dysmotility, has been associated with an increase in IELs (in the absence of villous atrophy) compared with healthy controls [85]. The prevalence of SIBO in ME was 4.5\% according to Kakar et al [9] and 22\% in a Spanish study [86]. In these cases, conditions causing stasis or recirculation of the intestinal contents are predisposing factors. Interestingly, SIBO was found to be associated with celiac disease that was not responsive to a gluten-free diet, thus suggesting a possible link between the two conditions [87].

\section{Immunoglobulin deficiencies}

The histologic aspects of the duodenum of patients affected by immunoglobulin deficiencies are often similar to those of celiac disease [88]. Moreover, patients with immunoglobulin deficiencies may report digestive symptoms in up to $50 \%$ of cases [89] and this may impede the differential diagnosis.

Selective IgA deficiency is the most widespread primary immunoglobulin deficiency, due to altered regulation of the final maturation of $\mathrm{B}$ lymphocytes into IgA-producing plasma cells [90]. Selective IgA deficiency implies an increased risk of concomitant celiac disease. Indeed, the prevalence of celiac disease in selective IgA deficiency is higher than in the general population, ranging from $6.7-20.6 \%$ [91,92]. On the other hand, selective IgA deficiency is more common in celiac patients, with a prevalence of $1-39 \%$ [93]. Common variable immunodeficiency is a heterogeneous group of primary immunoglobulin deficiencies characterized by low serum levels of immunoglobulins and a downregulated response to specific antigens, with a high risk of respiratory and gastrointestinal infections [94]. Although the estimated prevalence is 1:2550,000 , common variable immunodeficiency is considered to be the most frequent symptomatic immunoglobulin deficiency [94]. The diagnosis is based on reduced levels of IgG and IgA. Selective IgM deficiency is an extremely rare disorder, defined by low levels of IgM [95] in the absence of alterations of other immunoglobulin classes. In adults, the prevalence is about 1:15,000 [96]. Gastrointestinal phenomena are observed in $15.7 \%$ of patients with selective IgM deficiency, and some studies have demonstrated an association between celiac disease and selective IgM deficiency [97,98]. Interestingly, IgM levels return to normal in most pediatric and adult patients after a gluten-free diet [99]. 
The histopathological prototype of immunoglobulin deficiency has frequently been reported as a sprue-like picture, similar to celiac disease, with atrophy of villi and intraepithelial lymphocytosis. Some clues may help to distinguish between immunoglobulin deficiency and celiac disease. For instance, unlike celiac disease, common variable immunodeficiency should be suspected when plasma cells are reduced or absent in the lamina propria [100-102]. Biagi et al [103] stated that the histologic response to a gluten-free diet is the only reliable tool for establishing a diagnosis. Other authors suggested that HLA determination may be helpful [104]. Finally, a familial connection between celiac disease and common variable immunodeficiency has been hypothesized [105].

\section{Drugs}

Non-steroidal anti-inflammatory drugs (NSAIDs) and aspirin are widespread drugs, given for various indications (pain control, osteoarthritis, rheumatologic and cardiovascular disorders). An association with ME has been observed in $14-29.5 \%$ of patients $[9,12]$. NSAIDs are a well-known risk factor for gastric ulcers and erosions, but they are also a cause of similar damage to the small bowel [106]. In a study of patients with ankylosing spondylitis under NSAID treatment, duodenal mucosal lymphocytic infiltration was found in $83.3 \%$ of patients compared to $48.6 \%$ of controls [107]. Epithelial loss may be the consequence of a direct drug effect, while enterohepatic recirculation may increase the damage. In a murine model, villous ischemia elicited by slowing of villous blood flow and breaks to microvasculature have been identified as a further pathogenic mechanism [108]. In addition, in a rat model, indomethacin showed a direct proliferative effect on IELs [109].

Olmesartan is an antihypertensive drug that has recently been implicated in several cases of sprue-like enteropathy, with villous atrophy mimicking celiac disease [110,111]. In all the reports in the literature, drug withdrawal was effective in both stopping diarrhea and reversing mucosal damage. Other drugs of the same class were not linked to this histopathologic and clinical condition [112]. The pathogenesis of olmesartaninduced enteropathy is unclear, but it shares many features with celiac disease, including symptoms and immune-pathogenic pathways, such as increased numbers of CD8+ cells and corresponding overexpression of IL15 by epithelial cells [113].

\section{Hematological malignancies}

The digestive system may be affected by several types of lymphomatous disorders. Both B- and T-cell lymphomas have been described. The most common B-cell hematological malignancies affecting the intestine are MALT lymphoma, follicular lymphoma, mantle cell lymphoma and diffuse large B-cell lymphoma [114-117]. These subsets of disorders express a monoclonal proliferation of B-lymphocytes that infiltrate the mucosal layer, thus conferring a picture of ME. Enteropathy-associated T-cell lymphoma is a monoclonal disorder due to malignant degeneration of IELs. Two subtypes have been described: type 1 and 2, according to the different immunohistochemical phenotype. Type 1 in particular may be a complication of refractory celiac disease and is characterized by CD30 expression and singular chromosomal anomalies, such as 9q31.3 duplication or 16q12.1 deletion [118,119].

Graft-versus-host disease is a common complication following allogeneic hematopoietic cell transplantation that typically exhibits skin, gastrointestinal and liver injury. An immune reaction of transplanted bone marrow cells against the recipient underlies this condition. In intestinal graft versus host disease, the histological pattern may mimic both celiac disease (IEL accumulation and villous atrophy) and inflammatory bowel disease (ulcerations, cryptitis, crypt abscesses), thus prompting a differential diagnosis [120-122].

\section{Irritable bowel syndrome}

Irritable bowel syndrome is a functional disorder characterized by a group of symptoms, including abdominal pain and changes in the pattern of bowel movements, without any evidence of underlying damage [123]. Despite this definition, several reports have evidenced that a local inflammatory status may underlie this form [124]. Barbara et al, for example, have shown a crowding of degranulating mast cells close to mucosal nerves [125].

On this basis, several studies have highlighted mild IEL infiltration in the duodenum of irritable bowel syndrome patients. Spiller et al first demonstrated that, in postinfective diarrheal irritable bowel syndrome, there was an increase in IELs compared to controls, paralleling an increase in gut permeability [126]. Sundin et al [127] observed an increase in aberrant CD4+/CD8+ mucosal lymphocytes in both colonic lamina propria and epithelium in subjects with post-infectious IBS. In a series of 100 cases of ME, Aziz et al [128] reported an irritable bowel syndrome prevalence of $18 \%$. Remes Troche et al [129] reported a mean IEL count in irritable bowel syndrome of $16.7 \pm 6$ per 100 enterocytes, significantly lower than in celiac disease. An increase in duodenal IELs was seen even in the constipation variant of irritable bowel syndrome [130], thus emphasizing that a microscopic inflammatory change may trigger this "functional" condition.

\section{Causes of ME: a panorama}

In conclusion, our overview of the etiology of $\mathrm{ME}$ emphasizes the heterogeneity of this "umbrella term". Studies [9-11,72,128,131,132] attempting to elucidate the prevalence of the different underlying factors are summarized in Table 1. It is evident that the most frequent causes of ME are common conditions, such as gluten-related disorders, $H$. pylori and drugs. However, some reports claim that an apparent cause of ME fails to be detected in a very high percentage of cases. However, in most cases long-term surveillance leads to 
Table 1 Prevalence and conditions associated with microscopic enteritis

\begin{tabular}{|c|c|c|c|c|c|c|c|}
\hline Conditions & $\begin{array}{c}\text { Kakar [9] } \\
(\mathrm{n}=43)(\%)\end{array}$ & $\begin{array}{l}\text { Mahadeva [10] } \\
\qquad(\mathrm{n}=14)(\%)\end{array}$ & $\begin{array}{l}\text { Hammer [131] } \\
(\mathrm{n}=100)(\%)\end{array}$ & $\begin{array}{l}\text { Shmidt [11] } \\
(\mathrm{n}=48)(\%)\end{array}$ & $\begin{array}{c}\text { Aziz [128] } \\
(\mathrm{n}=100)(\%)\end{array}$ & $\begin{array}{l}\text { Losurdo [132] } \\
\qquad(\mathrm{n}=85)(\%)\end{array}$ & $\begin{array}{c}\text { Rosinach [72] } \\
(\mathrm{n}=90)(\%)\end{array}$ \\
\hline $\mathrm{CD}$ & 9 & 21 & 18 & 19 & 16 & 27 & 70 \\
\hline NCGS & - & - & & - & - & 22 & - \\
\hline $\begin{array}{l}\text { Tropical } \\
\text { sprue }\end{array}$ & 2 & - & 1 & - & - & - & - \\
\hline H. pylori & - & - & 6 & 6 & 14 & 6 & 50 \\
\hline $\begin{array}{l}\text { SIBO/other } \\
\text { infections }\end{array}$ & 5 & - & 3 & - & - & - & 6 \\
\hline Drugs & 14 & - & 8 & 20 & 21 & - & 13 \\
\hline IBD & 12 & - & 8 & 11 & 2 & 5 & - \\
\hline $\begin{array}{l}\text { Autoimmune } \\
\text { conditions }\end{array}$ & 14 & - & 6 & - & 4 & 2 & - \\
\hline Unexplained & 7 & 21 & 26 & 33 & 34 & - & 9 \\
\hline IBS & 9 & 14 & 20 & - & - & 38 & - \\
\hline Other & 28 & 43 & 4 & 11 & 9 & - & - \\
\hline
\end{tabular}

In some studies, the sum of percentages is more than $100 \%$ when more than one cause of microscopic enteritis was detected

CD, celiac disease; NCGS, non-celiac gluten sensitivity; SIBO, small intestinal bacterial overgrowth; IBD, inflammatory bowel disease; IBS, irritable bowel syndrome; H. pylori, Helicobacter pylori

a final diagnosis, since a hidden or quiescent condition may be disclosed after a latency period.

\section{Natural history, clinical features and diagnosis}

As mentioned above, in about a third of patients a suitable cause is not found when ME is initially detected (Table 1). Therefore, the follow up of the "so-called" idiopathic ME often allows a final diagnosis to be achieved. In the previous experience of our group [132], after a 2-year period of surveillance, $49 \%$ of patients developed a gluten-related disease ( $27 \%$ celiac disease and $22 \%$ non-celiac gluten sensitivity) and a large proportion were diagnosed with irritable bowel syndrome (38\%). In a series of patients with Marsh I lesions, 50\% showed worsening of their histological picture (Marsh III) after a mean period of 25 months, and anti-transglutaminase positivity was strongly predictive of this event [133]. Aziz et al [134] demonstrated that the evolution of ME towards celiac disease may be predicted by a family history of this disorder (odds ratio 6.73), HLA DQ positive status and anti-transglutaminase levels more than 3 times the upper normal limit. Moreover, we have shown that the increased mucosal expression of some inflammatory mediators may predict the evolution towards a gluten-related disorder, in particular tissue transglutaminase, and interferon- $\gamma$ could discriminate between the future development of celiac disease rather than non-celiac gluten sensitivity with a specificity of $87.1 \%$ and $96.77 \%$, respectively despite a low sensitivity (about 50\%) [135].

The clinical framework of ME is extremely heterogeneous, owing to the large variety of its etiology. Despite a macroscopically normal small bowel, microscopic and sub- microscopic abnormalities consistent with ME may induce a malabsorption syndrome. This phenomenon may be linked to the activation of local and systemic cytokines that trigger the inhibition of nutrient uptake. Although the malabsorption is less evident than in the presence of severe mucosal atrophy, it has been demonstrated that the clinical presentation and the entity of nutrient deficiency do not correlate with the degree of villous atrophy, and a lack of micro and macronutrients may occur even in Marsh I lesions [21,22,136]. The most commonly described conditions are iron, folate, B12 vitamin and vitamin D deficiencies [21,22,132]. Diarrhea and abdominal pain are the most common symptoms in ME. Other clinical features are specific of the disease underlying ME: dyspepsia or epigastric pain may be associated with $H$. pylori infection, recurrent infections with immunoglobulin deficiencies, or the coexistence of rhinitis, asthma and/or urticaria with allergic diseases.

On this basis, the differential diagnosis of ME should be driven by predominant symptoms and patient history (Fig. 3). Exposure to drugs and improvement in the symptoms after their withdrawal may strongly suggest the diagnosis. Extraintestinal manifestations fitting with celiac disease, anemia and diarrhea may be associated with gluten-related disorders, thus suggesting that specific serology should be determined. A gluten challenge according to the Salerno criteria is indicated for non-specific gluten sensitivity. Dyspeptic symptoms and/ or iron deficiency anemia in young people should nudge the clinician in the direction of $H$. pylori gastritis. Bloody diarrhea, anemia and weight loss may raise the suspicion of inflammatory bowel disease; therefore, fecal calprotectin, colonoscopy and eventually small bowel magnetic resonance could be useful. A history of recurrent infections should prompt immunoglobulin profiling to investigate deficiencies. 
The coexistence of urticaria with asthma or other respiratory symptoms may suggest wheat allergy or other allergies; therefore, allergy investigations such as a prick test, patch test or assay of IgE antigliadin may be indicated. Once further causes of ME have been ruled out, irritable bowel syndrome is plausible. In this context, HLA haplotype characterization may be very useful for ruling out gluten-related diseases, given the optimal negative predictive value of the test $[137,138]$.

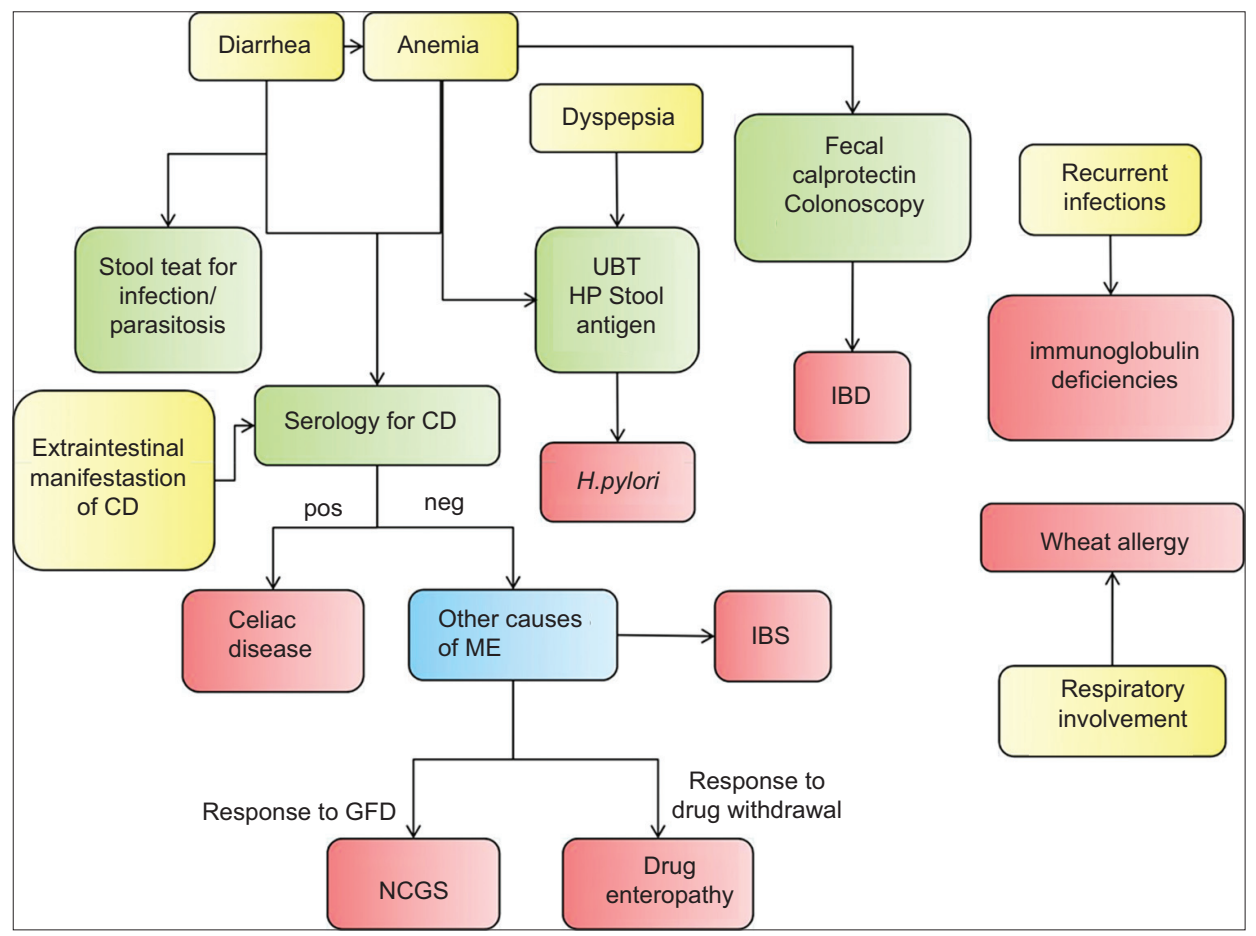

Figure 3 Proposal for a diagnostic algorithm for microscopic enteritis (ME)

$C D$, celiac disease; UBT, urea breath test; HP, Helicobacter pylori; IBD, inflammatory bowel disease; GFD, gluten-free diet; NCGS, non-celiac gluten sensitivity; IBS, irritable bowel syndrome

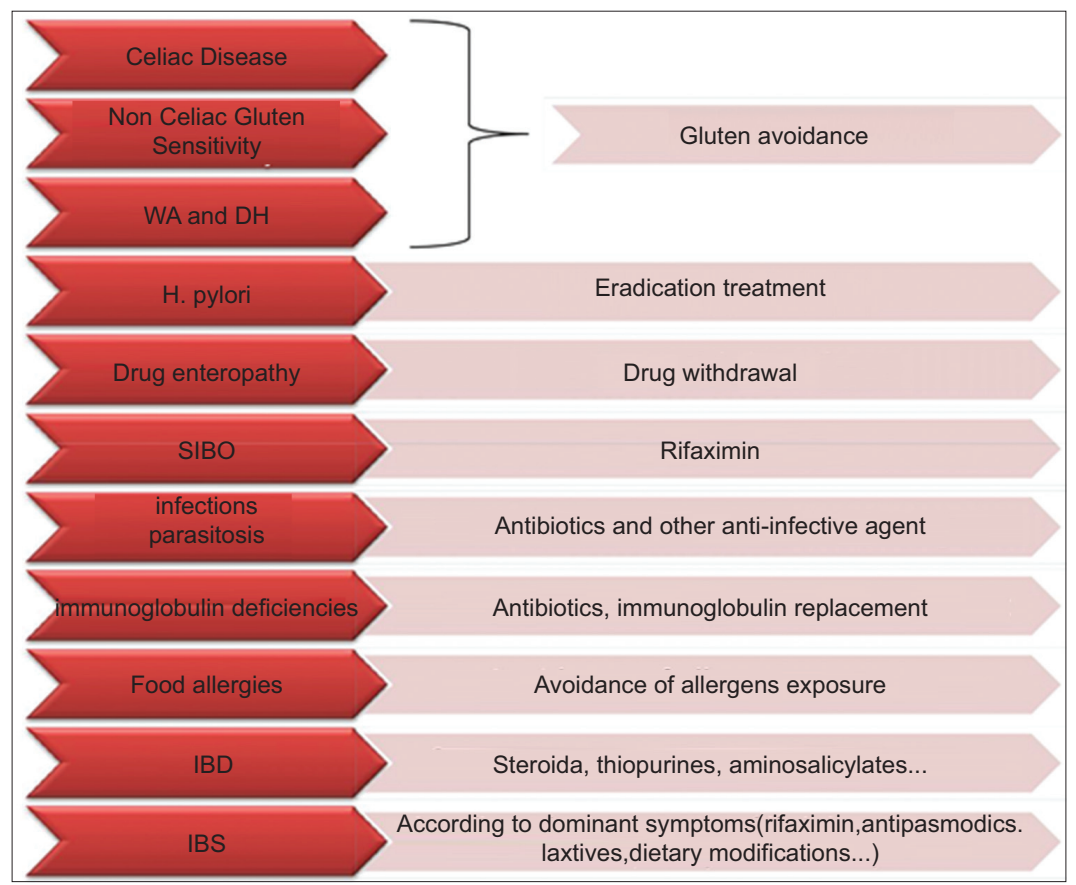

Figure 4 Figure summarizing possible treatments for microscopic enteritis according to the underlying disease

WA, wheat allergy; DH, dermatitis herpetiformis; SIBO, small intestinal bacterial overgrowth; IBD, inflammatory bowel disease; IBS, irritable bowel syndrome 
A possible diagnostic algorithm for $\mathrm{ME}$ is summarized in Fig. 3.

\section{Treatment}

The treatment of ME is personalized and depends on the underlying disease. For gluten-related conditions (celiac disease, non-celiac gluten sensitivity, wheat allergy, dermatitis herpetiformis), a gluten-free diet may be proposed, and it has demonstrated good effectiveness as regards symptom improvement and reversal of microscopic lesions [137]. For H. pylori-related duodenal lymphocytosis, eradication therapy should be proposed $[139,140]$. Antibiotics have shown effectiveness in both bacteria eradication and ME reversal [76]. Other intestinal infections require treatment that is targeted according to the etiologic agent, such as metronidazole for Giardia spp, rifaximin for SIBO, or fluoroquinolones for other bacterial species [141-143]. When the damage is sustained by drugs, withdrawal or switching to another class may be effective in curing ME [144]. For food allergies, avoidance of allergens is required [145]. As we know, the treatment of inflammatory bowel disease is based on several drug combinations, including aminosalicylates, steroids, antibiotics, thiopurines and biologic agents, according to the disease extension and severity, as recommended by guidelines [146,147]. Autoimmune enteropathy and other autoimmune conditions may require steroids and/or other immunosuppressive regimens [59]. Rare conditions, such as graft-versus-host disease, hematologic malignancies and immunoglobulin deficiencies, should be managed by a multidisciplinary dedicated team.

The therapy of irritable bowel syndrome is extremely varied, and needs to be personalized according to its subtype (diarrhea or constipation), following the Rome foundation report. The most currently used drugs encompass rifaximin, probiotics, prebiotics, fibers, antispasmodics, laxatives and dietary interventions [148-155].

In conclusion, the treatment of ME is complex and should be tailored for each patient, as reported in Fig. 4. A correct diagnosis, however, is necessary to guarantee the most indicated therapy and the best outcome.

\section{Concluding remarks}

ME is a heterogeneous condition, which thus represents a real challenge for the gastroenterologist. However, due to the complexity of the problem, the clinical approach needs interaction with other specialists, such as pathologists, immunologists, hematologists, allergists and laboratory medicine specialists. The challenge for the future will be the definition of novel methodologies to improve the diagnosis and treatment. At the moment, the state of the art requires an adequately skilled clinician.

\section{Acknowledgment}

The authors would like to thank Vito Bellomo for assistance with the graphical presentations.

\section{References}

1. Hammer ST, Greenson JK. The clinical significance of duodenal lymphocytosis with normal villus architecture. Arch Pathol Lab Med 2013;137:1216-1219.

2. Rostami K, Aldulaimi D, Holmes G, et al. Microscopic enteritis: Bucharest consensus. World J Gastroenterol 2015;21:2593-2604.

3. Rostami K, Villanacci V. Microscopic enteritis: novel prospect in coeliac disease clinical and immuno-histogenesis. Evolution in diagnostic and treatment strategies. Dig Liver Dis 2009;41:245-252.

4. Robert ME. Gluten sensitive enteropathy and other causes of small intestinal lymphocytosis. Semin Diagn Pathol 2005;22:284-294.

5. Dickson BC, Streutker CJ, Chetty R. Coeliac disease: an update for pathologists. J Clin Pathol 2006;59:1008-1016.

6. Crowe PT, Marsh MN. Morphometric analysis of intestinal mucosa. VI-Principles in enumerating intra-epithelial lymphocytes. Virchows Arch 1994;424:301-306.

7. Marsh MN. Gluten, major histocompatibility complex, and the small intestine. A molecular and immunobiologic approach to the spectrum of gluten sensitivity ('celiac sprue'). Gastroenterology 1992;102:330-354.

8. Galli G, Purchiaroni F, Lahner E, et al. Time trend occurrence of duodenal intraepithelial lymphocytosis and celiac disease in an open access endoscopic population. United European Gastroenterol J 2016 (in press).

9. Kakar S, Nehra V, Murray JA, Dayharsh GA, Burgart LJ. Significance of intraepithelial lymphocytosis in small bowel biopsy samples with normal mucosal architecture. Am J Gastroenterol 2003;98:2027-2033.

10. Mahadeva S, Wyatt JI, Howdle PD. Is a raised intraepithelial lymphocyte count with normal duodenal villous architecture clinically relevant? J Clin Pathol 2002;55:424-428.

11. Shmidt E, Smyrk TC, Faubion WA, Oxentenko AS. Duodenal intraepithelial lymphocytosis with normal villous architecture in pediatric patients: Mayo Clinic experience, 2000-2009. J Pediatr Gastroenterol Nutr 2013;56:51-55.

12. Shmidt E, Smyrk TC, Boswell CL, Enders FT, Oxentenko AS. Increasing duodenal intraepithelial lymphocytosis found at upper endoscopy: time trends and associations. Gastrointest Endosc 2014;80:105-111.

13. Abadie V, Discepolo V, Jabri B. Intraepithelial lymphocytes in celiac disease immunopathology. Semin Immunopathol 2012;34:551-566.

14. Forsberg G, Hernell O, Hammarström S, Hammarström ML. Concomitant increase of IL-10 and pro-inflammatory cytokines in intraepithelial lymphocyte subsets in celiac disease. Int Immunol 2007;19:993-1001.

15. Lundqvist C, Melgar S, Yeung MM, Hammarström S, Hammarström ML. Intraepithelial lymphocytes in human gut have lytic potential and a cytokine profile that suggest T helper 1 and cytotoxic functions. J Immunol 1996;157:1926-1934.

16. Ogata M, Ota Y, Matsutani T, Nanno M, Suzuki R, Itoh T. Granzyme B-dependent and perforin-independent DNA fragmentation in intestinal epithelial cells induced by anti-CD3 mAb-activated intra-epithelial lymphocytes. Cell Tissue Res 2013;352:287-300.

17. Camarca A, Del Mastro A, Gianfrani C. Repertoire of gluten peptides active in celiac disease patients: perspectives for translational therapeutic applications. Endocr Metab Immune 
Disord Drug Targets 2012;12:207-219.

18. Gianfrani C, Auricchio S, Troncone R. Adaptive and innate immune responses in celiac disease. Immunol Lett 2005;99:141-145.

19. Jiang W, Wang X, Zeng B, et al. Recognition of gut microbiota by NOD2 is essential for the homeostasis of intestinal intraepithelial lymphocytes. J Exp Med 2013;210:2465-2476.

20. Fasano A, Catassi C. Clinical practice. Celiac disease. N Engl J Med 2012;367:2419-2426.

21. Zanini B, Caselani F, Magni A, et al. Celiac disease with mild enteropathy is not mild disease. Clin Gastroenterol Hepatol 2013;11:253-258.

22. Zanini B, Lanzarotto F, Villanacci V, Carabellese N, Ricci C, Lanzini A. Clinical expression of lymphocytic duodenosis in "mild enteropathy" celiac disease and in functional gastrointestinal syndromes. Scand J Gastroenterol 2014;49:794-800.

23. Tursi A, Brandimarte G, Giorgetti G, Gigliobianco A, Lombardi D, Gasbarrini G. Low prevalence of antigliadin and anti-endomysium antibodies in subclinical/silent celiac disease. Am J Gastroenterol 2001;96:1507-1510.

24. Volta U, Caio G, Boschetti E, et al. Seronegative celiac disease: Shedding light on an obscure clinical entity. Dig Liver Dis 2016;48:1018-1022.

25. Ierardi E, Losurdo G, Piscitelli D, et al. Seronegative celiac disease: where is the specific setting? Gastroenterol Hepatol Bed Bench 2015;8:110-116.

26. Auricchio R, Tosco A, Piccolo E, et al. Potential celiac children: 9-year follow-up on a gluten-containing diet. Am J Gastroenterol 2014;109:913-921.

27. Ierardi E, Amoruso A, Giorgio F, et al. Mucosal molecular pattern of tissue transglutaminase and interferon gamma in suspected seronegative celiac disease at Marsh 1 and 0 stages. Saudi J Gastroenterol 2015;21:379-385.

28. Leffler D, Vanga R, Mukherjee R. Mild enteropathy celiac disease: a wolf in sheep's clothing? Clin Gastroenterol Hepatol 2013;11:259-261.

29. Fasano A, Sapone A, Zevallos V, Schuppan D. Nonceliac gluten sensitivity. Gastroenterology 2015;148:1195-1204.

30. Volta U, De Giorgio R. New understanding of gluten sensitivity. Nat Rev Gastroenterol Hepatol 2012;9:295-299.

31. Sapone A, Lammers KM, Casolaro V, et al. Divergence of gut permeability and mucosal immune gene expression in two glutenassociated conditions: celiac disease and gluten sensitivity. $B M C$ Med 2011;9:23.

32. Caio G, Riegler G, Patturelli M, Facchiano A, DE Magistris L, Sapone A. Pathophysiology of non-celiac gluten sensitivity: where are we now? Minerva Gastroenterol Dietol 2017;63:16-21.

33. Volta U, Tovoli F, Cicola R, et al. Serological tests in gluten sensitivity (nonceliac gluten intolerance). J Clin Gastroenterol 2012;46:680-685.

34. De Giorgio R, Volta U, Gibson PR. Sensitivity to wheat, gluten and FODMAPs in IBS: facts or fiction? Gut 2016;65:169-178.

35. Zevallos VF, Raker V, Tenzer S, et al. Nutritional wheat amylasetrypsin inhibitors promote intestinal inflammation via activation of myeloid cells. Gastroenterology 2017;152:1100-1113.e12.

36. Carroccio A, Rini G, Mansueto P. Non-celiac wheat sensitivity is a more appropriate label than non-celiac gluten sensitivity. Gastroenterology 2014;146:320-321.

37. Aziz I, Lewis NR, Hadjivassiliou M, et al. A UK study assessing the population prevalence of self-reported gluten sensitivity and referral characteristics to secondary care. Eur J Gastroenterol Hepatol 2014;26:33-39.

38. Catassi C, Elli L, Bonaz B, et al. Diagnosis of non-celiac gluten sensitivity (NCGS): the Salerno experts' criteria. Nutrients 2015;7:4966-4977.

39. Elli L, Tomba C, Branchi F, et al. Evidence for the presence of non-celiac gluten sensitivity in patients with functional gastrointestinal symptoms: results from a multicenter randomized double-blind placebo-controlled gluten challenge. Nutrients 2016;8:84.

40. Francavilla R, Cristofori F, Castellaneta S, et al. Clinical, serologic, and histologic features of gluten sensitivity in children. J Pediatr 2014;164:463-467.e1.

41. Catassi C, Bai JC, Bonaz B, et al. Non-celiac gluten sensitivity: the new frontier of gluten related disorders. Nutrients 2013;5:3839-3853.

42. Villanacci V, Lanzini A, Lanzarotto F, Ricci C. Observations on the paper of Carroccio et al. "non-celiac wheat sensitivity diagnosed by double-blind placebo-controlled challenge: exploring a new clinical entity". Am J Gastroenterol 2013;108:619-620.

43. Carroccio A, Mansueto P, Iacono G, et al. Non-celiac wheat sensitivity diagnosed by double-blind placebo-controlled challenge: exploring a new clinical entity. Am J Gastroenterol 2012;107:1898-1906.

44. Czaja-Bulsa G, Bulsa M. What do we know now about IgEmediated wheat allergy in children? Nutrients 2017;9. doi: 10.3390/ nu9010035.

45. Keet CA, Matsui EC, Dhillon G, Lenehan P, Paterakis M, Wood RA. The natural history of wheat allergy. Ann Allergy Asthma Immunol 2009;102:410-415.

46. Czaja-Bulsa G, Bulsa M. The natural history of IgE mediated wheat allergy in children with dominant gastrointestinal symptoms. Allergy Asthma Clin Immunol 2014;10:12.

47. Mansouri M, Pourpak Z, Mozafari H, Abdollah Gorji F, Shokouhi Shoormasti R. Follow-up of the wheat allergy in children; consequences and outgrowing the allergy. Iran J Allergy Asthma Immunol 2012;11:157-163.

48. Matsuo H, Dahlström J, Tanaka A, et al. Sensitivity and specificity of recombinant omega-5 gliadin-specific IgE measurement for the diagnosis of wheat-dependent exercise-induced anaphylaxis. Allergy 2008;63:233-236.

49. Carroccio A, Mansueto P, D’Alcamo A, Iacono G. Non-celiac wheat sensitivity as an allergic condition: personal experience and narrative review. Am J Gastroenterol 2013;108:1845-1852.

50. Salmi TT, Hervonen K, Kautiainen H, Collin P, Reunala T. Prevalence and incidence of dermatitis herpetiformis: a 40-year prospective study from Finland. Br J Dermatol 2011;165:354-359.

51. Rose C, Armbruster FP, Ruppert J, Igl BW, Zillikens D, Shimanovich I. Autoantibodies against epidermal transglutaminase are a sensitive diagnostic marker in patients with dermatitis herpetiformis on a normal or gluten-free diet. J Am Acad Dermatol 2009;61:39-43.

52. Savilahti E, Ormälä T, Arato A, et al. Density of gamma/delta+ T cells in the jejunal epithelium of patients with coeliac disease and dermatitis herpetiformis is increased with age. Clin Exp Immunol 1997;109:464-467.

53. Vecchi M, Crosti L, Berti E, Agape D, Cerri A, De Franchis R. Increased jejunal intraepithelial lymphocytes bearing gamma/ delta T-cell receptor in dermatitis herpetiformis. Gastroenterology 1992;102:1499-1505.

54. Reunala T, Kosnai I, Karpati S, Kuitunen P, Török E, Savilahti E. Dermatitis herpetiformis: jejunal findings and skin response to gluten free diet. Arch Dis Child 1984;59:517-522.

55. Vitoria JC, Camarero C, Sojo A, Ruiz A, Rodriguez-Soriano J. Enteropathy related to fish, rice, and chicken. Arch Dis Child 1982;57:44-48.

56. Stern M, Dietrich R, Müller J. Small intestinal mucosa in coeliac disease and cow's milk protein intolerance: morphometric and immunofluorescent studies. Eur J Pediatr 1982;139:101-105.

57. Pesce G, Pesce F, Fiorino N, et al. Intraepithelial gamma/deltapositive $\mathrm{T}$ lymphocytes and intestinal villous atrophy. Int Arch Allergy Immunol 1996;110:233-237. 
58. Kokkonen J, Holm K, Karttunen TJ, Mäki M. Children with untreated food allergy express a relative increment in the density of duodenal gammadelta $+\mathrm{T}$ cells. Scand J Gastroenterol 2000;35:1137-1142.

59. Gentile NM, Murray JA, Pardi DS. Autoimmune enteropathy: a review and update of clinical management. Curr Gastroenterol Rep 2012;14:380-385.

60. Marthinsen LM, Scott H, Ejderhamn J. Autoimmune enteropathy in Swedish children, 1985-2002: a call for strict diagnostic criteria. Scand J Gastroenterol 2008;43:1102-1107.

61. Masia R, Peyton S, Lauwers GY, Brown I. Gastrointestinal biopsy findings of autoimmune enteropathy: a review of 25 cases. Am J Surg Pathol 2014;38:1319-1329.

62. Diaz L, Hernandez-Oquet RE, Deshpande AR, Moshiree B. Upper Gastrointestinal involvement in Crohn disease: histopathologic and endoscopic findings. South Med J 2015;108:695-700.

63. Patterson ER, Shmidt E, Oxentenko AS, Enders FT, Smyrk TC. Normal villous architecture with increased intraepithelial lymphocytes: a duodenal manifestation of Crohn disease. Am J Clin Pathol 2015;143:445-450.

64. Vidali F, Di Sabatino A, Broglia F, et al. Increased CD8+ intraepithelial lymphocyte infiltration and reduced surface area to volume ratio in the duodenum of patients with ulcerative colitis. Scand J Gastroenterol 2010;45:684-689.

65. Kokkonen J, Arvonen M, Vähäsalo P, Karttunen TJ. Intestinal immune activation in juvenile idiopathic arthritis and connective tissue disease. Scand J Rheumatol 2007;36:386-389.

66. Casis B, Fernández-Vázquez I, Barnardos E, et al. Autoimmune enteropathy in an adult with autoimmune multisystemic involvement. Scand J Gastroenterol 2002;37:1012-1016.

67. Ning-Sheng L, Ruay-Sheng L, Kuo-Chih T. High frequency of unusual gastric/duodenal ulcers in patients with Behçet's disease in Taiwan: a possible correlation of MHC molecules with the development of gastric/duodenal ulcers. Clin Rheumatol 2005;24:516-520.

68. Cindoruk M, Tuncer C, Dursun A, et al. Increased colonic intraepithelial lymphocytes in patients with Hashimoto's thyroiditis. J Clin Gastroenterol 2002;34:237-239.

69. Michaëlsson G, Kraaz W, Hagforsen E, Pihl-Lundin I, Lööf L, Scheynius A. The skin and the gut in psoriasis: the number of mast cells and CD3+ lymphocytes is increased in non-involved skin and correlated to the number of intraepithelial lymphocytes and mast cells in the duodenum. Acta Derm Venereol 1997;77:343-346.

70. Rodrigo L, Hernández-Lahoz C, Fuentes D, Alvarez N, LópezVázquez A, González S. Prevalence of celiac disease in multiple sclerosis. BMC Neurol 2011;11:31.

71. Lebwohl B, Blaser MJ, Ludvigsson JF, et al. Decreased risk of celiac disease in patients with Helicobacter pylori colonization. Am J Epidemiol 2013;178:1721-1730.

72. Rosinach M, Esteve M, González C, et al. Lymphocytic duodenosis: aetiology and long-term response to specific treatment. Dig Liver Dis 2012;44:643-648.

73. Simondi D, Ribaldone DG, Bonagura GA, et al. Helicobacter pylori in celiac disease and in duodenal intraepithelial lymphocytosis: active protagonist or innocent bystander? Clin Res Hepatol Gastroenterol 2015;39:740-745.

74. Memeo L, Jhang J, Hibshoosh H, Green PH, Rotterdam H, Bhagat G. Duodenal intraepithelial lymphocytosis with normal villous architecture: common occurrence in $H$. pylori gastritis. Mod Pathol 2005; 18:1134-1144.

75. Nahon S, Patey-Mariaud De Serre N, Lejeune O, et al. Duodenal intraepithelial lymphocytosis during Helicobacter pylori infection is reduced by antibiotic treatment. Histopathology 2006;48:417-423.

76. Guz-Mark A, Zevit N, Morgenstern S, Shamir R. Duodenal intraepithelial lymphocytosis is common in children without coeliac disease, and is not meaningfully influenced by Helicobacter pylori infection. Aliment Pharmacol Ther 2014;39:1314-1320.

77. Yoshida N, Granger DN, Evans DJ Jr, et al. Mechanisms involved in Helicobacter pylori-induced inflammation. Gastroenterology 1999;105:1431-1440.

78. Rostami-Nejad M, Javad Ehsani-Ardakani M, Assadzadeh H, et al. Pathological and clinical correlation between celiac disease and Helicobacter pylori infection; a review of controversial reports. Middle East J Dig Dis 2016;8:85-92.

79. Rostami Nejad M, Rostami K, Yamaoka Y, et al. Clinical and histological presentation of Helicobacter pylori and gluten related gastroenteropathy. Arch Iran Med 2011;14:115-118.

80. Cama VA, Mathison BA. Infections by intestinal coccidia and Giardia duodenalis. Clin Lab Med 2015;35:423-444.

81. Lewis DJ, Freedman AR. Giardia lamblia as an intestinal pathogen. Dig Dis 1992;10:102-111.

82. Santos RB, Fonseca LE Jr, Santana AT, Silva CA, Guedes JC. Clinical, endoscopic and histopathological profiles of parasitic duodenitis cases diagnosed by upper digestive endoscopy. Arq Gastroenterol 2011;48:225-230.

83. Ferguson A, McClure JP, Townley RR. Intraepithelial lymphocyte counts in small intestinal biopsies from children with diarrhoea. Acta Paediatr Scand 1976;65:541-546.

84. Brown IS, Bettington A, Bettington M, Rosty C. Tropical sprue: revisiting an underrecognized disease. Am J Surg Pathol 2014;38:666-672.

85. Riordan SM, McIver CJ, Wakefield D, Duncombe VM, Thomas MC, Bolin TD. Small intestinal mucosal immunity and morphometry in luminal overgrowth of indigenous gut flora. Am J Gastroenterol 2001;96:494-500.

86. Santolaria S, Dominguez M, Alcedo J, et al. [Lymphocytic duodenosis: etiological study and clinical presentations]. Gastroenterol Hepatol 2013;36:565-573.

87. Losurdo G, Marra A, Shahini E, et al. Small intestinal bacterial overgrowth and celiac disease: A systematic review with pooleddata analysis. Neurogastroenterol Motil 2017;29. doi: 10.1111/ nmo.13028.

88. Giorgio F, Principi M, Losurdo G, et al. Seronegative celiac disease and immunoglobulin deficiency: where to look in the submerged iceberg? Nutrients 2015;7:7486-7504.

89. Agarwal S, Mayer L. Diagnosis and treatment of gastrointestinal disorders in patients with primary immunodeficiency. Clin Gastroenterol Hepatol 2013;11:1050-1063.

90. Brandtzaeg P. Update on mucosal immunoglobulin A in gastrointestinal disease. Curr Opin Gastroenterol 2010;26:554-563.

91. Wang N, Truedsson L, Elvin K, et al. Serological assessment for celiac disease in IgA deficient adults. PLoS One 2014;9:e93180.

92. Lenhardt A, Plebani A, Marchetti F, et al. Role of humantissue transglutaminase IgG and anti-gliadin IgG antibodies in the diagnosis of coeliac disease in patients with selective immunoglobulin A deficiency. Dig Liver Dis 2004;36:730-734.

93. Wang N, Shen N, Vyse TJ, et al. Selective IgA deficiency in autoimmune diseases. Mol Med 2011;17:1383-1396.

94. Abolhassani H, Sagvand BT, Shokuhfar T, Mirminachi B, Rezaei N, Aghamohammadi A. A review on guidelines for management and treatment of common variable immunodeficiency. Expert Rev Clin Immunol 2013;9:561-574.

95. Dati F, Schumann G, Thomas L, et al. Consensus of a group of professional societies and diagnostic companies on guidelines for interim reference ranges for 14 proteins in serum based on the standardization against the IFCC/BCR/CAP Reference Material (CRM 470). International Federation of Clinical Chemistry. Community Bureau of Reference of the Commission of the European Communities. College of American Pathologists. Eur J Clin Chem Clin Biochem 1996;34:517-520. 
96. Ohno T, Inaba M, Kuribayashi K, Masuda T, Kanoh T, Uchino H. Selective IgM deficiency in adults: phenotypically and functionally altered profiles of peripheral blood lymphocytes. Clin Exp Immunol 1987;68:630-637.

97. Hobbs JR, Hepner GW. Deficiency of M-globulin in coeliac disease. Lancet 1968;291:217-220.

98. Brown DL, Cooper AG, Hepner GW. IgM metabolism in coeliac disease. Lancet 1969;1:858-861.

99. Montenegro L, Piscitelli D, Giorgio F, et al. Reversal of IgM deficiency following a gluten-free diet in seronegative celiac disease. World J Gastroenterol 2014;20:17686-17689.

100. Lougaris V, Ravelli A, Villanacci V, et al. Gastrointestinal pathologic abnormalities in pediatric- and adult-onset common variable immunodeficiency. Dig Dis Sci 2015;60:2384-2389.

101. Malamut G, Verkarre V, Suarez F, et al. The enteropathy associated with common variable immunodeficiency: the delineated frontiers with celiac disease. Am J Gastroenterol 2010;105:2262-2275.

102. Luzi G, Zullo A, Iebba F, et al. Duodenal pathology and clinical-immunological implications in common variable immunodeficiency patients. Am J Gastroenterol 2003;98:118-121.

103. Biagi F, Bianchi PI, Zilli A, et al. The significance of duodenal mucosal atrophy in patients with common variable immunodeficiency: a clinical and histopathologic study. Am J Clin Pathol 2012;138:185-189.

104. Venhoff N, Emmerich F, Neagu M, et al. The role of HLA DQ2 and DQ8 in dissecting celiac-like disease in common variable immunodeficiency. J Clin Immunol 2013;33:909-916.

105. Licinio R, Principi M, Amoruso A, Piscitelli D, Ierardi E, Di Leo A. Celiac disease and common variable immunodeficiency: a familial inheritance? J Gastrointestin Liver Dis 2013;22:473.

106. Wallace JL. Mechanisms, prevention and clinical implications of nonsteroidal anti-inflammatory drug-enteropathy. World $J$ Gastroenterol 2013;19:1861-1876.

107. Lamarque D, Nhieu JT, Breban M, et al. Lymphocytic infiltration and expression of inducible nitric oxide synthase in human duodenal and colonic mucosa is a characteristic feature of ankylosing spondylitis. J Rheumatol 2003;30:2428-2436.

108. Kelly DA, Piasecki C, Anthony A, Dhillon AP, Pounder RE, Wakefield AJ. Focal reduction of villous blood flow in early indomethacin enteropathy: a dynamic vascular study in the rat. Gut 1998;42:366-373.

109. Ross DS, Roy TR. Potentiation of rat colon intraepithelial lymphocyte (IEL) natural killer (NK) activity with indomethacin. Adv Exp Med Biol 1987;216A:527-531.

110. Ianiro $G$, Bibbò $S$, Montalto $M$, Ricci $R$, Gasbarrini $A$, Cammarota G. Systematic review: sprue-like enteropathy associated with olmesartan. Aliment Pharmacol Ther 2014:40:16-23.

111. Rubio-Tapia A, Herman ML, Ludvigsson JF, et al. Severe spruelike enteropathy associated with olmesartan. Mayo Clin Proc 2012;87:732-738.

112. Greywoode R, Braunstein ED, Arguelles-Grande C, Green PH, Lebwohl B. Olmesartan, other antihypertensives, and chronic diarrhea among patients undergoing endoscopic procedures: a case-control study. Mayo Clin Proc 2014;89:1239-1243.

113. Marietta EV, Nadeau AM, Cartee AK, et al. Immunopathogenesis of olmesartan-associated enteropathy. Aliment Pharmacol Ther 2015;42:1303-1314.

114. Ruskone-Fourmestraux A, Delmer A, Hennequin C. Gastrointestinal lymphomas. Gastroenterol Clin Biol 2006;30 Spec No 2:2S81-2S90.

115. Ruskoné-Fourmestraux A, Audouin J. Primary gastrointestinal tract mantle cell lymphoma as multiple lymphomatous polyposis. Best Pract Res Clin Gastroenterol 2010;24:35-42.
116. Daum S, Thiel E, Zeitz M. Is intestinal diffuse large B cell lymphoma a relatively benign disease? Leuk Res 2007;31:287-289.

117. Iwamuro M, Kondo E, Takata K, Yoshino T, Okada H. Diagnosis of follicular lymphoma of the gastrointestinal tract: A better initial diagnostic workup. World J Gastroenterol 2016;22:1674-1683.

118. Ondrejka S, Jagadeesh D. Enteropathy-associated T-cell lymphoma. Curr Hematol Malig Rep 2016;11:504-513.

119. Rishi AR, Rubio-Tapia A, Murray JA. Refractory celiac disease. Expert Rev Gastroenterol Hepatol 2016;10:537-546.

120. Woodman I, Schofield JB, Haboubi N. The histopathological mimics of inflammatory bowel disease: a critical appraisal. Tech Coloproctol 2015;19:717-727.

121. Peled JU, Hanash AM, Jenq RR. Role of the intestinal mucosa in acute gastrointestinal GVHD. Blood 2016;128:2395-2402.

122. Washington K, Jagasia M. Pathology of graft-versus-host disease in the gastrointestinal tract. Hum Pathol 2009;40:909-917.

123. De Giorgio R, Barbara G, Stanghellini V, et al. Diagnosis and therapy of irritable bowel syndrome. Aliment Pharmacol Ther 2004;20(Suppl 2):10-22.

124. De Giorgio R, Barbara G. Is irritable bowel syndrome an inflammatory disorder? Curr Gastroenterol Rep 2008;10:385-390.

125. Barbara G, Stanghellini V, De Giorgio R, et al. Activated mast cells in proximity to colonic nerves correlate with abdominal pain in irritable bowel syndrome. Gastroenterology 2004;126:693-702.

126. Spiller RC, Jenkins D, Thornley JP, et al. Increased rectal mucosal enteroendocrine cells, T lymphocytes, and increased gut permeability following acute Campylobacter enteritis and in post-dysenteric irritable bowel syndrome. Gut 2000;47:804-811.

127. Sundin J, Rangel I, Kumawat AK, Hultgren-Hörnquist E, Brummer RJ. Aberrant mucosal lymphocyte number and subsets in the colon of post-infectious irritable bowel syndrome patients. Scand J Gastroenterol 2014;49:1068-1075.

128. Aziz I, Evans KE, Hopper AD, Smillie DM, Sanders DS. A prospective study into the aetiology of lymphocytic duodenosis. Aliment Pharmacol Ther 2010;32:1392-1397.

129. Remes-Troche JM, Adames K, Castillo-Rodal AI, et al. Intraepithelial gammadelta+ lymphocytes: a comparative study between celiac disease, small intestinal bacterial overgrowth, and irritable bowel syndrome. J Clin Gastroenterol 2007;41:671-676.

130. Walker MM, Talley NJ, Prabhakar M, et al. Duodenal mastocytosis, eosinophilia and intraepithelial lymphocytosis as possible disease markers in the irritable bowel syndrome and functional dyspepsia. Aliment Pharmacol Ther 2009;29:765-773.

131. Hammer STG, Maneerattanaporn M, Rude K, et al. Duodenal lymphocytosis with normal villous architecture: How often is it celiac disease? Mod Pathol 2010;23(Suppl 1):146A.

132. Losurdo G, Piscitelli D, Giangaspero A, et al. Evolution of nonspecific duodenal lymphocytosis over 2 years of follow-up. World J Gastroenterol 2015;21:7545-7552.

133. Singh P, Lauwers GY, Garber JJ. Outcomes of seropositive patients with Marsh 1 histology in clinical practice. J Clin Gastroenterol 2016;50:619-623.

134. Aziz I, Key T, Goodwin JG, Sanders DS. Predictors for celiac disease in adult cases of duodenal intraepithelial lymphocytosis. J Clin Gastroenterol 2015;49:477-482.

135. Losurdo G, Giorgio F, Piscitelli D, et al. May the assessment of baseline mucosal molecular pattern predict the development of gluten related disorders among microscopic enteritis? World J Gastroenterol 2016;22:8017-8025.

136. Brar P, Kwon GY, Egbuna II, et al. Lack of correlation of degree of villous atrophy with severity of clinical presentation of coeliac disease. Dig Liver Dis 2007;39:26-29.

137. Ludvigsson JF, Bai JC, Biagi F, et al; British Society of Gastroenterology. Diagnosis and management of adult coeliac 
disease: guidelines from the British Society of Gastroenterology. Gut 2014;63:1210-1228.

138. Wolters VM, Wijmenga C. Genetic background of celiac disease and its clinical implications. Am J Gastroenterol 2008;103:190-195.

139. Ierardi E, Giorgio F, Losurdo G, Di Leo A, Principi M. How antibiotic resistances could change Helicobacter pylori treatment: A matter of geography? World J Gastroenterol 2013;19:8168-8180.

140. Malfertheiner P, Megraud F, O'Morain CA, et al; European Helicobacter and Microbiota Study Group and Consensus panel. Management of Helicobacter pylori infection-the Maastricht V/ Florence Consensus Report. Gut 2017;66:6-30.

141. Escobedo AA, Cimerman S. Giardiasis: a pharmacotherapy review. Expert Opin Pharmacother 2007;8:1885-1902.

142. Gatta L, Scarpignato C. Systematic review with meta-analysis: rifaximin is effective and safe for the treatment of small intestine bacterial overgrowth. Aliment Pharmacol Ther 2017;45:604-616.

143. DuPont HL. Persistent diarrhea: a clinical review. JAMA 2016;315:2712-2723.

144. Marietta EV, Cartee A, Rishi A, Murray JA. Drug-induced enteropathy. Dig Dis 2015;33:215-220.

145. Nowak-Wegrzyn A, Szajewska H, Lack G. Food allergy and the gut. Nat Rev Gastroenterol Hepatol 2017;14:241-257.

146. Dignass A, Lindsay JO, Sturm A, et al. Second European evidence-based consensus on the diagnosis and management of ulcerative colitis part 2: current management. J Crohns Colitis 2012;6:991-1030.

147. Dignass A, Van Assche G, Lindsay JO, et al; European Crohn's and Colitis Organisation (ECCO). The second European evidence- based Consensus on the diagnosis and management of Crohn's disease: Current management. J Crohns Colitis 2010;4:28-62.

148. Guandalini S, Cernat E, Moscoso D. Prebiotics and probiotics in irritable bowel syndrome and inflammatory bowel disease in children. Benef Microbes 2015;6:209-217.

149. Laterza L, Ianiro G, Scoleri I, et al. Rifaximin for the treatment of diarrhoea-predominant irritable bowel syndrome. Expert Opin Pharmacother 2015;16:607-615.

150. Scarpellini E, Laterza L, Ianiro G, Tack J, Abenavoli L, Gasbarrini A. Eluxadoline for the treatment of diarrhoea-predominant irritable bowel syndrome. Expert Opin Pharmacother 2016;17:1395-1402.

151. Nagarajan N, Morden A, Bischof D, et al. The role of fiber supplementation in the treatment of irritable bowel syndrome: a systematic review and meta-analysis. Eur J Gastroenterol Hepatol 2015;27:1002-1010.

152. Sainsbury A, Ford AC. Treatment of irritable bowel syndrome: beyond fiber and antispasmodic agents. Therap Adv Gastroenterol 2011;4:115-127.

153. Shah SL, Lacy BE. Dietary interventions and irritable bowel syndrome: a review of the evidence. Curr Gastroenterol Rep 2016;18:41.

154. Lacy BE, Levenick JM, Crowell MD. Linaclotide: a novel therapy for chronic constipation and constipation-predominant irritable bowel syndrome. Gastroenterol Hepatol (N Y) 2012;8:653-660.

155. Drossman DA. Functional gastrointestinal disorders: history, pathophysiology, clinical features and Rome IV. Gastroenterology. 2016 Feb 19. doi: 10.1053/j.gastro.2016.02.032. [Epub ahead of print]. 